\title{
Fundamentals for the Allocation of Financial Benefits in Virtual Enterprises
}

\author{
Hendrik Jähn and Thomas Burghardt \\ Chemnitz University of Technology, Dept. of Economic Sciences, Thüringer Weg 7 \\ 09126 Chemnitz, Germany \\ \{hendrik.jaehn, thomas.burghardt\} @wirtschaft.tu-chemnitz.de
}

\begin{abstract}
In the following fundamentals for the allocation of financial benefits such as profit are introduced. The content is based on the concept of valueadding process-related virtual enterprises. Before applying exact rules for the calculation and allocation of the financial benefits some initial process steps need to be completed. That is indispensable for the success of virtual enterprises because financial benefits are the main target of economic activities. The development of relevant approaches is based on the framework of the new institutional economics. Thereby, informational asymmetries, opportunistic behaviour, a limited rationality and an individual maximisation of utility are the basic assumptions. Considering the fundamentals of profit allocation forms an integral component of the operative management of cooperations.
\end{abstract}

Keywords: Allocation, Value Creation, Trust Modeling, Virtual Enterprise.

\section{Motivation}

Over the last two decades the intensified academic focus on the management of enterprise networks and virtual enterprises has led to a vast number of academic publications describing innovative approaches that are used to shape processes and solve problems more effectively from various view points and with different objectives. The research within this subject area is characterized by a great variety of concepts and a heterogeneous terminology as well as by the handling of issues based on very specific foundations and assumptions. The network management concept "Extended Value Chain Management" (EVCM) [1] was developed as one part of specific research projects that focussed enterprise networks. EVCM is an extensive approach for the generation and operation of order-specifically configured production networks and virtual enterprises focussing especially on small and medium-sized enterprises (SME). Enterprises in EVCM-coordinated value-added networks retain their legal and economic independence and also act as equal partners and compete for customer orders. In that context many processes have to be modelled and implemented. Apart from procedures concerning the generation and operation of the cooperation, there are others that have to be considered as well, for instance, procedures focussing on the delivery of the finished product to the customer. Against 
this backdrop, the allocation of profit or loss acquires a special importance. For that reason, an extensive study has been conducted dealing with possibilities of profit allocation within order-specifically configured production networks and virtual enterprises. Profit allocation in virtual enterprises is a very specific task because several economic independent enterprises cooperate on one project or order but the amount paid by the customer needs to allocated in a justified manner. This contribution focuses that problem by considering mainly the foundations.

\section{Possibilities of a Profit Allocation}

Possibilities for allocating financial benefits in cooperations are divided in a practical perspective focussing some experiences from different areas of application and a theoretical perspective represented by a literature review. In most cooperations, regardless of what particular type, it is common that the partaking enterprises calculate their profit as part of their offer. In such cases there is no need for an explicit mechanism for profit distribution. However, it is still unclear how to handle outstanding customer payments, deficit complaints, or product liability claims. At this point, it becomes apparent how important it is to look at these problems.

According to a study of the economy institute of the trade chamber Bozen, Italy from the year 2000, there are clearly defined rules concerning the profit distribution in $77 \%$ of all industrial co-operations. This is contrasted by only $13 \%$ in handy craft businesses. Since it can be assumed that the participation of enterprises in cooperations is based on their agreement to the corresponding terms and conditions, it follows that many enterprises are likely to underestimate the significance of precise regulations concerning the allocation of financial benefits. Such deficits, however, may have a negative effect on the success of cooperations. For this reason, it was recommended to establish fixed regulations based on a contract e.g. concerning the profit and loss distribution during enterprise cooperations. It is advisable to reach a consensus concerning all regulations before the value-added process starts.

Berg et al. [2] presented an empirical investigation focusing on operating companies in the agrarian sector. In the context of a review representatives of 24 companies from the North Rhine Westphalian area in Germany were interviewed. Interviews focussed the profit determination and distribution (factor remuneration and distribution solutions). It was found out that the remuneration is based on the production factors that enter the total profit of the joint venture. This could consist out of beneficial interests for real estate, and to a minor extend soil and contingents. Live stock, machines, and supplies are considered as well during remuneration. Later on, the profit which is left after the completion of the remuneration is to be distributed. With respect to the invested capital, most companies use a distribution-key for this matter. Since the factor remuneration has a higher priority, it is common to distribute the profit at this particular stage. The distribution-key may range from a ratio of 90:10 up to 50:50. In case of a loss, two thirds of all co-operations have fixed rules concerning the loss distribution which work similar to the profit distribution. 
Approaches from game theory have a different take on the problem. In a concrete case, three enterprises form the area of Karlsruhe, Germany were trying to reduce the costs for their energy supply through the building of an energy supply plant. The profit in this case assumes the form of the reduced costs made visible through a reference case without an energy conservation plan [3]. Depending on the particular approach, different solutions are possible in this case.

The problem of profit distribution is addressed mostly superficially in academic literature. Schuh and Strack recommend a profit distribution which is based on the participation during the value-creation process. This can be accomplished through negotiations or through the application of solution principles that are typical for the market and that are ultimately all based on pre-defined parameters [4]. The remuneration should at least correspond to the opportunity costs of the missed utilization of the resources either in or for once own enterprise, plus, a corresponding profit share [5]. According to Borchardt, it is advisable for the cooperation partners of a Virtual Enterprise to clarify all questions concerning the profit distribution and the coordination costs already during negotiation phase [6]. In that context, transfer prices on the basis of full costs in addition to profit shares offer the best solution.

Krajewska and Kopfer consider a concrete field of application by focussing on the logistics sector [7]. The available approaches to this problem all assume similar power relations and similar market positions of the involved partners. Most of these approaches are designed for a short-term application and they are based on ideas from Operations Research, game theory, and combinational auctions. Every co-operation partner has to disclose the lowest possible fulfilment costs. Through an aggregation of the presented offers, a portfolio is created for the sake of maximizing the profit of the whole cooperation. The whole model is of a theoretic nature.

A simple proposal is introduced by Schönsleben and Hieber [8]. They suggest an equal division of the additional profit which results from the co-operation-based value-added process (e.g. the profit from a cost reduction or increased earnings) because this particular profit is not merely the result of an individual effort, but that of an effective partnership.

Jin and $\mathrm{Wu}$ [9] present an approach which puts the mechanisms for the development of co-operations of suppliers at the centre of their work. Hereby auctions are the preferred tool because of their simplicity and efficiency that made them a very popular form of price fixing in eCommerce. The two components of a specific cooperation mechanism are the development of a coalition through the search for suitable members and the profit distribution among these members. The profit distribution which is based on the individual profit expectations is a key function for the development of a cooperation since it is possible to start the auction mechanism with this knowledge. Additionally there are further approaches that can be found in academic literature which are rather rudimental and therefore are not included here.

\section{A Framework for the Allocation Model}

In the following basic information about the framework for the allocation model is introduced. In addition basic assumptions and its interdependencies are considered. 
The operator concept EVCM for the coordination of value-added processes presents a phase model which describes the typical life cycle phases of a cooperation. Depending on the situation, EVCM can work automatically, so that a high degree of self-organization is achieved. One objective of the EVCM is to select those enterprises that are most suitable for cooperation. Following the reception of a customer request the value-added process is decomposed into its individual process steps. For every step at least one enterprise has to be selected. It has to possess not only the required resources, but also the necessary competencies. The result of this work planning is a process variants plan which includes several options for manufacturing of the product. In the following, an inquiry is sent to the selected enterprises inquiring the capability of providing the necessary resources by considering their capacity situation. Additionally soft-facts, such as co-operation and communication abilities as well as reliability, are considered as well. When the ideal network configuration is found the production process starts. After its completion and delivery, every partaking enterprise is assessed in terms of the produced effort and the obtained profit (or loss) is distributed among the involved enterprises.

As already mentioned there are several options to allocate financial benefits in networked structures. In order to account for the large number of cooperation scenarios, several approaches, which can be applied depending on the particular circumstances, have already been developed [10]. In some cases enterprises have to reveal their profit expectations. Another important point to be considered is the enterprise-related costs during the planned value-added process. It must be differentiated in fixed and variable costs. The variable costs are directly allocable to the product. The fixed costs arise independently from a specific order. They are added to the particular order or to the product through the application of some costaccounting approaches. The extent to which the enterprises add costs to the customer order is to be determined only by the enterprises. The mechanisms of price formation have to be observed carefully. In the beginning, the revenue matches the accumulated costs since the profit is determined separately. There is an option to establish a lower price limit in the form of a contribution margin that equals zero by determining the variable costs as the total costs of an enterprise, that is, the revenue would equal the variable costs. The standard case, however, presents an appropriate contribution margin in order to cover the fixed costs of an enterprise as well.

In the following, some possibilities of how to determine the obtained net profit will be examined closer. The starting point is that a customer places an order on the basis of an enterprise offer to manufacture a product. The basis for all this is a mutual declaration of intent concerning the quality of the product, the amount and price as well as further relevant criteria. It is also assumed that all required competencies that are necessary for the manufacturing of the product can be provided by the enterprises from the resource pool. After the completion of the value-added process and the delivery of the final product, the customer pays the agreed price. Subsequently, a performance analysis and the profit allocation are realized.

In principle, it is not necessary to have the enterprises calculate their individual profit directly in the offer price. It must also be assumed that several resource pool enterprises share the same core competencies and, therefore, compete for the same 
customer orders. This constellation is explicitly welcomed since this guarantees that some enterprises do not work overpriced due to the competition. Obviously, this would drastically reduce their chances for being selected. If an enterprise secretly calculates profits into its offers, it is doing this at its own risk. The most important information in all allocation approaches to production nets with $n$ enterprises is $c_{j}$. That is the costs related to the value-added process. The fixing of $c_{j}$ occurs during the assignation of the individual offers to the corresponding process steps. These costs can be calculated into the value-added process either directly or indirectly. The sum of all enterprise-specific costs $c_{i}$ is $C$. The total costs are the basis for the offer that is submitted to the customer by the network. During that phase EVCM has to add a network-related calculative offer profit $G^{\text {offer }}$ before the final offer price $P^{\text {offer }}$ for a product can be calculated. The offer price $P^{\text {offer }}$ is the amount that the customer has to pay after the delivery of the product. To determine the offer price, cf. equation 1 .

$$
P^{\text {offer }}=C+G^{\text {offer }} \text {. }
$$

The net profit $G^{\text {offer }}$ that was determined by EVCM is calculated on the basis of an algorithm and, if necessary, through the application of negotiation mechanisms. The algorithm that is used in order to determine the offer profit is presented extensively in section 4 . It is apparent that the enterprises $\operatorname{costs} c_{i}$, which were calculated into the purchase price, can now be safely assigned. The difference between the selling price $P^{\text {sell }}$ and the sum of the individual cost shares of the total costs $C$ results in profit $G$.

\section{Determination of Profit}

In the following the basic procedure and an algorithm for the determination of the allocable financial benefit of a production process in a Virtual Enterprise is introduced. During the request process the enterprises have to reveal a variety of data to the EVCM. One of the most important variables is the enterprise-related cost $c_{i}$. Another relevant variable is the fixed cost share $c_{i}^{f i x}$ relating to a particular valueadded process. In addition, it is expected that an enterprise that is being requested by the EVCM also reveals its individual profit expectation $g_{i}{ }_{i}$. It can be expressed in different ways and is deposited as a master data record of the particular enterprise. The individual profit expectation is independent from a value-added process.

A central component of the network offer is the offer price $P^{\text {offer }}$. That variable is the sum of the total costs $C$ related to the order and the offer profit $G^{\text {offer }}$. While the total costs represent all value added process-related costs of an enterprise $c_{i}$, the offer profit has to be calculated seperately. Thus, a characteristic organization procedure occurs: In order to allocate a profit, a value-added process has to be fulfilled. Here for a customer order has to be initiated. This, however, presupposes an active offer. In order to create an offer, the offer profit $G^{\text {offer }}$ is required, which must be determined according to a allocation approach. Therefore, it is necessary to clarify which of the available profit allocation approaches is to be applied. The enterprise-specific profit expectation $g_{i}{ }^{e}$ are important for determining the offer profit $G^{\text {offer }}$. This value can be expressed in the form of a percentage of the value-added process of an enterprise $g_{i}^{e p}$. 
Absolute values $g_{i}{ }^{e}$ that depend on the specific cost shares of an enterprise $c_{i}$ are an option as well. Both of these variables can be set in relation, cf. equation 2 .

$$
g_{i}^{e}=g_{i}^{e p} \cdot c_{i} .
$$

A principal procedure for determining the offer profit is illustrated in fig. 1. The algorithm is presented next by utilizing calculation formulas for individual variables.

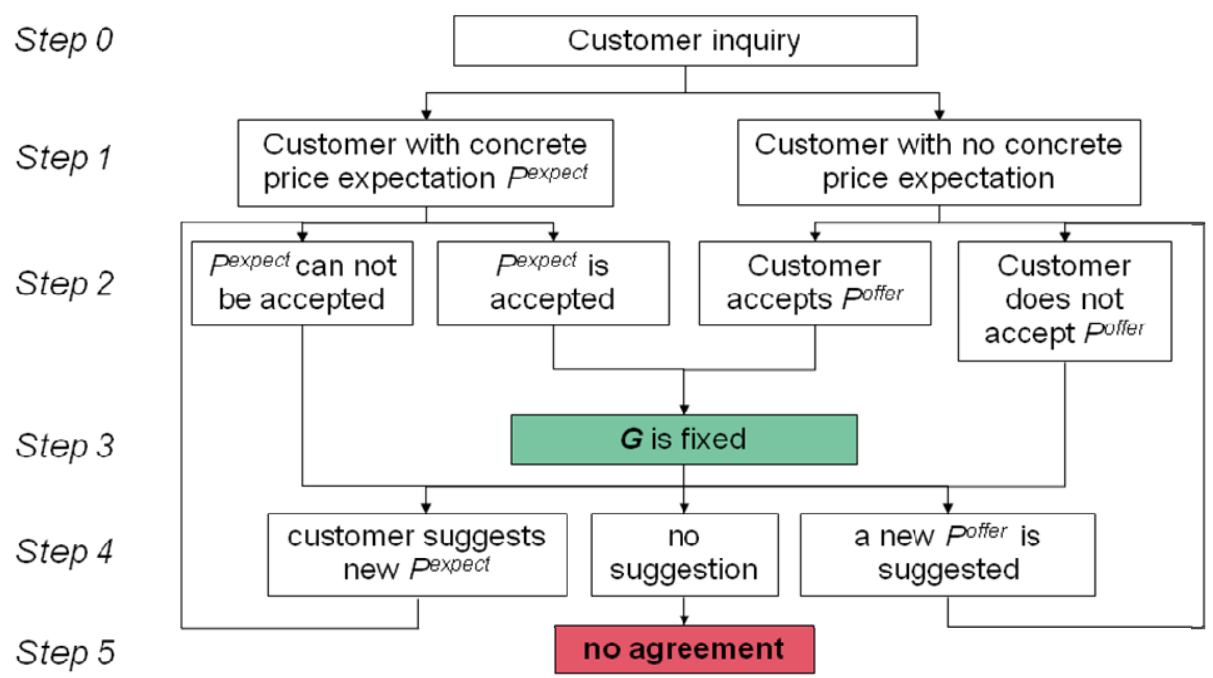

Fig. 1. Diagram depicting the determination of important figures

After the reception of the customer inquiry, it must be differentiated whether the customer presents an expected price $P^{\text {expect }}$ or not. In case of a concrete purchase price $P^{\text {expect }}$, it is possible to calculate the realizable profit $G^{r}$ of the order straight away without any further preconditions. This can be done by subtracting the total costs of the network $C$ from the expected price $P^{\text {expect }}$, cf. equation 3.

$$
G^{r}=P^{\text {expect }}-C \text {. }
$$

Subsequently, it must be clarified whether the individual enterprises are satisfied with their calculative profit shares. For this, the realizable profit $G^{r}$ from equation 3 has to be divided among the enterprises partaking in the value-added process based on the chosen profit allocation model. The resulting variable is expressed as $g_{i}^{r}$ and should at least correspond with the individual profit expectation $g_{i}{ }^{e}$. It may occur that not all enterprises are satisfied with their calculative profit share because it is lower than expected. In order to solve this problem, a majority decision should be found. This procedure, however, could be very dissatisfying, particularly in the case of ambiguous results. Therefore, an alternative could be to sum-up all individual absolute profit expectations $g_{i}{ }^{e}$ to $G^{e}$. Adding the complete profit expectations $G^{e}$ to the total costs $C$ 
results in the offer price $P^{\text {offer }}$ (see equation 1). It must be noted, however, that at this point $G^{e}$ is not the same as $G^{\text {offer }}$.

Now, the expected price of the customer $P^{\text {expect }}$ (including the realizable profit $G^{r}$ ) and the preliminary realizable offer price $P^{\text {offer }}$ (including the sum of the profit expectation of the enterprise $G^{e}$ ) can be laid out. A comparison of these two variables leads to two possible options. If the preliminary offer price of the complete network $P^{\text {offer }}$ exceeds the expected price of the customer $P^{\text {expect }}$ (the sum of the individual profit expectations $G^{e}$ is higher than the realizable profit $G^{r}$ ), it can assumed that the enterprises will not accept the expected price $P^{\text {expect }}$ because they cannot attain their expected profits. In this case, EVCM will take appropriate measures, for instance, further negotiations between EVCM and the potential customer. These kinds of mechanisms represent step four of the algorithm. Overall, some parameters may be altered in order to reach a contract agreement. If the realizable offer price of the net $P^{\text {offer }}$ is lower than the expected price of the customer $P^{\text {expect }}$ or corresponds to it, then this expected price $P^{\text {expect }}$ will be accepted. An additional profit can be obtained. The customer will accept this offer because the realizable profit $G^{r}$ exceeds the sum of the profit expectations $G^{e}$. The difference $G^{d}$ occurs:

$$
G^{d}=G^{r}-G^{e} .
$$

This difference profit $G^{d}$ represents a back-up or incentive payments as well as shared among the enterprises based on an extended profit distribution model. At this point, $G^{o f f e r}$, which was calculated into $P^{\text {offer }}$, is determined conclusively.

$$
G^{\text {offer }}=P^{\text {offer }}-C .
$$

Alternatively, there is also the possibility when the customer suggests a concrete price expectation. In this case, the customer is presented an offer. The following procedure appears adequate in this respect: Starting with an individual profit expectation for the enterprise $g_{i}^{e}$, it is possible to determine the sum of the profit expectations of the entire network $G_{e}$. $G_{e}$ is then added to the total costs of the net $C$ which results in a preliminary offer price $P^{\text {offer }}$ which is presented to the customer.

$$
P^{\text {offer }}=C+G^{e} \text {. }
$$

Then, if the offer suits the customer, he will accept it. With this, the offer profit $G^{\text {offer }}$ corresponds to the sum of the profit expectations $G_{e}$ and is now fixed. It follows:

$$
G^{\text {offer }}:=G^{e} .
$$

The situation becomes more complicated, if the customer rejects the offer. In this case it has is assumed that despite the non-existence of a concrete price expectation $P^{\text {expect }}$, the customer still has a concrete price expectation. The offer apparently exceeds this secret price expectation $P^{\text {expect }}$. This requires the start of negotiations.

Three different alternatives for a further proceeding appear after completing the negotiation process. The first option is that the customer presents a new higher price expectation $P^{\text {expect }}$. That means, the customer is willing to pay more than at the previous stage. At this stage the algorithm leads to the two already discussed 
alternatives. The second option is an alteration of the offer price by EVCM. Through the partial or complete disclaimer of the offer profit $G^{\text {offer }}$ the offer price can be further reduced. Here again, step two follows: The customer can either accept the offer or not - this would trigger the corresponding consequences. It is also possible that the two parties are not willing to make any further suggestions. Consequently, no agreement can be reached meaning that there can be no conclusion of a contract.

Under a careful analysis, it becomes apparent that the first two options are related to one another. The main aim of these activities is to reach an agreement concerning the purchase price. If the price expectation of the customer is below the offer price of the network, then either the price expectation has to be increased or the offer price has to be reduced. The presented algorithm allows executing several iteration steps before an agreement is reached or the negations are aborted. It is, however, open which side takes over the initiative.

\section{Conclusion}

In this contribution the fundamentals for modeling approaches for a direct allocation of financial benefits such as profit or loss in order-specifically configured production nets and virtual enterprises were introduced. This primarily theoretic research work is required if decentralized distribution of financial figures, which is related to the valueadded process, is to be carried out in a as far as possible automated manner. It is fact that the research concerning the common practices has given little insights, so that a theoretical analysis was required at first. It became apparent that the problem has to be approached on a theoretical way which has to be further refined by the application of economically-relevant methods in order to arrive at an appropriate solution approach. An appropriate model has been presented in general terms. The big advantage of this model is that it is adaptable to a high degree and it is therefore suited as a general reference model. Future works will include a validation of the model. Then the focus is laid on modeling precise calculation approaches for the allocation of financial benefits in networks and its evaluation in a real-world environment.

\section{References}

1. Teich, T.: Extended Value Chain Management - Ein Konzept zur Koordination von Wertschöpfungsnetzen. Verlag der GUC, Chemnitz (2003)

2. Berg, E., Trenkel, H., Lüttgens, B., Grienberger, R., Möller, K., Reinders, M.: Motivation, Zielsetzung und innere Organisation von Betriebsgesellschaften in der Landwirtschaft. Betriebsgesellschaften in der Landwirtschaft - Chancen und Grenzen im Strukturwandel, $141-178$ (2001)

3. Frank, M.: Entwicklung und Anwendung einer integrierten Methode zur Analyse von betriebsübergreifenden Energieversorgungskonzepten. Dissertation, University Karlsruhe, TH (2003)

4. Schuh, G., Strack, J.: Virtualität in der produzierenden Industrie. Technologie und Management 48(1), 10-14 (1999) 
5. Steven, M.: Produktionsmanagement in virtuellen Unternehmen. ZFO 70(2), 86-92 (2001)

6. Borchardt, A.: Koordinationsinstrumente in virtuellen Unternehmen. Deutscher Universitäts-Verlag, Wiesbaden (2006)

7. Krajewska, M.A., Kopfer, H.: Profit sharing approaches for freight forwarders: An overview. In: Lukinsky, V.S., Uvarov, S.A., Koroleva, E.A. (eds.) Proceedings of the 5th International Scientific-Practical Conference Logistics: Modern Trends of Development, April 20-21, pp. 157-161. SPSUEE, Saint Petersburg, Russia (2006)

8. Schönsleben, P., Hieber, R.: Gestaltung von effizienten Wertschöpfungspartnerschaften im Supply Chain Management. In: Busch, A., Dangelmaier, W. (eds.) Integriertes Supply Chain Management, 2nd edn., pp. 47-64. Gabler, Wiesbaden (2004)

9. Jin, M., Wu, S.D.: Supplier coalitions in on-line reverse auctions: Validity requirements and profit distribution scheme. Int. Journal of Production Economics 100, 183-194 (2006)

10. Jähn, H., Fischer, M., Teich, T.: Distribution of Network Generated Profit by Considering Individual Profit Expectations. In: Camarinha-Matos, L.M., et al. (eds.) Establishing the Foundation of Collaborative Networks. IFIP, vol. 243, pp. 337-344. Springer, Boston (2007) 